\title{
Video Article \\ Using Flexible Gold-Titanium Reaction Cells to Simulate Pressure-Dependent Microbial Activity in the Context of Subsurface Biomining
}

\author{
Christian Ostertag-Henning ${ }^{1}$, Ruiyong Zhang ${ }^{1}$, Oliver Helten ${ }^{1}$, Thomas Weger ${ }^{1}$, Axel Schippers ${ }^{1}$ \\ ${ }^{1}$ Federal Institute for Geosciences and Natural Resources
}

Correspondence to: Christian Ostertag-Henning at christian.ostertag-henning@bgr.de

URL: https://www.jove.com/video/60140

DOI: doi:10.3791/60140

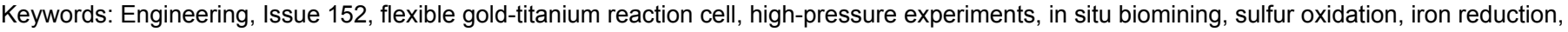
copper ore

Date Published: 10/5/2019

Citation: Ostertag-Henning, C., Zhang, R., Helten, O., Weger, T., Schippers, A. Using Flexible Gold-Titanium Reaction Cells to Simulate PressureDependent Microbial Activity in the Context of Subsurface Biomining. J. Vis. Exp. (152), e60140, doi:10.3791/60140 (2019).

\section{Abstract}

Laboratory studies investigating subsurface microbial processes, such as metal leaching in deep ore deposits (biomining), share common and challenging obstacles, including the special environmental conditions that need to be replicated, e.g., high pressure and in some cases acidic solutions. The former requires an experimental setup suitable for pressurization up to 100 bar, while the latter demands a fluid container with high chemical resistance against corrosion and unwanted chemical reactions with the container wall. To meet these conditions for an application in the field of in situ biomining, a special flexible gold-titanium reaction cell inside a rocking high-pressure reactor was used in this study. The described system allowed simulation of in situ biomining through sulfur-driven microbial iron reduction in an anoxic, pressure-controlled, highly chemically inert experimental environment. The flexible gold-titanium reaction cell can accommodate up to $100 \mathrm{~mL}$ of sample solution, which can be sampled at any given time point while the system maintains the desired pressure. Experiments can be performed on timescales ranging from hours to months. Assembling the high-pressure reactor system is fairly time consuming. Nevertheless, when complex and challenging (microbiological) processes occurring in the earth's deep subsurface in chemically aggressive fluids have to be investigated in the laboratory, the advantages of this system outweigh the disadvantages. The results found that even at high pressure the microbial consortium is active, but at significantly lower metabolic rates.

\section{Video Link}

The video component of this article can be found at https://www.jove.com/video/60140/

\section{Introduction}

During the past decade, efforts to minimize the impact of mining on the environment have increased. Open pit mining for the raw material extraction of ores (e.g., copper-rich sulfide ores), impacts the surrounding landscape by the excavation activities and by the large remaining volumes of waste rocks and remains of processed ore after the extraction of precious metals like copper. Extracting copper directly from the ore in the subsurface would significantly reduce these impacts. The technology of in situ biomining is a promising candidate for this process ${ }^{1}$. This publication describes the use of stimulated microbial activity to extract the precious metals from the ore into an aqueous solution in the subsurface. Thus, a copper-rich solution can be easily pumped back to the surface to further concentrate the metal, for example.

The activity of ore-leaching acidophilic microorganisms has been studied in many laboratories for a diverse array of parameters ${ }^{2,3,4,5,6}$. However, pressure effects on the microbial activity resulting from the difference between ambient surface lab conditions (near 1 bar) and the subsurface at a depth of $1,000 \mathrm{~m}$ with hydrostatic conditions ( $100 \mathrm{bar})$, are not well-documented. Therefore, the effects of pressure on microbial iron reduction have been investigated through different experimental avenues ${ }^{7}$. Here, the most suitable technique is described in detail.

High-pressure reactors have been used extensively to study reactions at pressures and temperatures occurring in the subsurface of the earth. Such reactors consist of a reactor vessel at the bottom that can contain a fluid sample with a microbial culture. Sitting on top of the reactor vessel, the reactor head offers a diverse array of connections and interfaces for safety measures and monitoring sensors (e.g., temperature or pressure). Most high-pressure reactors are made of stainless steel. This material offers high resilience and good machining properties, but the corrosion resistance of the stainless-steel surface is not adequate for every application. For example, if highly acidic or highly reducing aqueous solutions are investigated, significant reactions of the compounds of interest with the reactor wall may occur. One way to avoid this is to insert a liner into the reactor vessel, for instance a liner made from borosilicate glass ${ }^{7}$. It is easy to clean and can be sterilized by autoclaving. In addition, it is not attacked by acidic or reducing aqueous solutions. Even though a liner can help to prevent artificial reactions of the solution or microbes in the solution with the stainless-steel reactor wall, several problems remain. For one, if a corrosive gas is formed, such as hydrogen sulfide produced by sulfate-reducing bacteria, this gas might react with the uncovered surface of the reactor head sitting above the liner. Another disadvantage is that it is not possible to withdraw a sample from the reactor while maintaining the pressure.

To overcome these limitations, specialized flexible reaction cells inside the high-pressure reactors have been developed for a variety of applications. A flexible polytetrafluoroethylene (PTFE) cell ${ }^{8}$ was designed for solubility studies of salts in highly saline brines. However, the 
limitation of this system is that some gases can easily permeate the PTFE. In addition, this material still has a relatively low temperature stability. Thus, the system was improved by designing a flexible gold bag with a titanium head ${ }^{9}$ to be placed inside the stainless-steel high-pressure reactor. The gold surface is corrosion-resistant against acidic or reducing solutions and gases. The titanium surface is also highly inert when passivated thoroughly to form a continuous titanium dioxide layer. During sampling from this reaction cell through a connected titanium sampling tube, the gold bag shrinks in volume. The system's internal pressure is maintained by pumping the same volume of water, as is withdrawn by sampling, into the stainless-steel high-pressure reactor accommodating the reaction cell. The sample inside the reaction cell is kept in motion by rocking or tilting the high-pressure reactor by more than $90^{\circ}$ during the experiment.

The reaction cell consists of the parts depicted in Figure 1: the gold bag, titanium collar, titanium head, stainless steel washer, titanium compression bolt ring, titanium sampling tube with stainless glands and collars for the high-pressure coned and threaded connections on both sides, and the titanium valve. The gold bag is a cylindrical gold (Au 99.99) cell with a wall thickness of $0.2 \mathrm{~mm}$, an outer diameter of $48 \mathrm{~mm}$, and a length of $120 \mathrm{~mm}$.

All titanium parts are custom-made by the workshop from titanium grade 2 rods. The dimensions of the collar, head, washer, and compression bolt ring are visible in Figure 2. The titanium sampling tube is a capillary of titanium with an outer diameter of $6.25 \mathrm{~mm}$ and a wall thickness of $1.8 \mathrm{~mm}$, resulting in an inner diameter of $2.65 \mathrm{~mm}$. It is fixed into the titanium head and the titanium valve by high-pressure coned and threaded connections ensuring a seal of titanium-against-titanium surfaces. The high-pressure titanium valve is equipped with a slow opening stem to allow for very controlled opening or sampling even at high pressure. This system was used in numerous studies ${ }^{10,11,12}$.

\section{Preparation of the medium and inoculation of the microbial culture}

1. Prepare a basal salt medium for autotrophic prokaryotes according to published techniques ${ }^{13}$. Dissolve and mix the chemicals below in distilled water (mg/L): $\mathrm{Na}_{2} \mathrm{SO}_{4} \cdot 10 \mathrm{H}_{2} \mathrm{O}(150)\left(\mathrm{NH}_{4}\right)_{2} \mathrm{SO}_{4}(450), \mathrm{KCl}(50), \mathrm{MgSO}_{4} \cdot 7 \mathrm{H}_{2} \mathrm{O}(500), \mathrm{KH}_{2} \mathrm{PO}_{4}(50)$, and $\mathrm{Ca}\left(\mathrm{NO}_{3}\right)_{2} \cdot 4 \mathrm{H}_{2} \mathrm{O}(7)$.

2. Add $1 \mathrm{~mL} / \mathrm{L}$ of a $1,000 x$ concentrated trace element solution containing (g/L): $\mathrm{ZnSO}_{4} \cdot 7 \mathrm{H}_{2} \mathrm{O}(10), \mathrm{CuSO}_{4} \cdot 5 \mathrm{H}_{2} \mathrm{O}(1), \mathrm{MnSO}_{4} \cdot \mathrm{H}_{2} \mathrm{O}(0.76)$, $\mathrm{CoSO}_{4} \cdot 7 \mathrm{H}_{2} \mathrm{O}(1), \operatorname{CrK}\left(\mathrm{SO}_{4}\right)_{2} \cdot 12 \mathrm{H}_{2} \mathrm{O}(0.4), \mathrm{H}_{3} \mathrm{BO}_{3}(0.6), \mathrm{NaMoO}_{4} \cdot 2 \mathrm{H}_{2} \mathrm{O}(0.5), \mathrm{NiSO}_{4} \cdot 6 \mathrm{H}_{2} \mathrm{O}(1), \mathrm{Na}_{2} \mathrm{SeO}_{4}(0.51), \mathrm{Na}_{2} \mathrm{WO}_{4} \cdot 2 \mathrm{H}_{2} \mathrm{O}(0.1)$, and $\mathrm{NaVO}_{3}(0.1)$. Adjust the $\mathrm{pH}$ to 1.8 by adding $5 \mathrm{M}$ sulfuric acid.

3. Sterilize the medium in an autoclave at $121^{\circ} \mathrm{C}$ and 1.2 bar for $20 \mathrm{~min}$ and sterilize the ferric iron solution by filtration through a $0.22 \mu \mathrm{m}$ pore size syringe filter.

4. Transfer $50 \mathrm{~mL}$ of the sterilized basal salt medium into a serum bottle and add ferric iron solution and elemental sulfur to a final concentration of $50 \mathrm{mM}$ and $10 \mathrm{~g} / \mathrm{L}$, respectively.

5. Inoculate the medium with a mixed culture composed of several mesoacidophilic iron-oxidizing prokaryotes ${ }^{14}$.

6. Cap the serum bottle with sterilized butyl rubber stoppers and seal with aluminum crimps.

7. Vigorously bubble the culture medium with $\mathrm{N}_{2}$ to strip dissolved oxygen for $25 \mathrm{~min}$. Use two needles, place one deeper in the bottle head, the other one close to the cap.

8. Inject $\mathrm{CO}_{2}$ to obtain a $90 \% \mathrm{~N}_{2}$ and $10 \% \mathrm{CO}_{2}$ atmosphere in the headspace of the serum bottle. Incubate the culture without stirring at $30{ }^{\circ} \mathrm{C}$ in the dark.

\section{Preparation of the gold-titanium reaction cell and the high-pressure reactor}

1. Clean the gold-titanium reaction cell.

1. Disassemble the reaction cell into the individual parts to avoid the contact of acid with the stainless-steel parts, or the exposure of the assembled parts with different thermal expansion properties to heat.

2. Clean the surfaces that will be in contact with the sample during the experiment (i.e., the gold bag, the titanium head, titanium sampling tube, and titanium valve).

1. Put the gold bag and the titanium head in a glass beaker.

2. Add enough $10 \% \mathrm{HCl}$ to cover all the parts.

3. Heat the acid on a heating plate to $50{ }^{\circ} \mathrm{C}$ for $3 \mathrm{~h}$ while stirring it.

4. Remove the parts with PTFE tweezers from the acid solution and rinse them with deionized water.

5. Rinse the inner surface of the gold bag and the titanium head thoroughly with $65 \% \mathrm{HNO}_{3}$ and then with deionized water.

6. Rinse the inner surface of the titanium sampling tube and the titanium valve with $10 \% \mathrm{HCl}$, followed by deionized water, $65 \%$ $\mathrm{HNO}_{3}$, and then deionized water again.

7. Clean all parts from organic contamination by rinsing them with acetone.

8. Dry all parts in the oven at $105^{\circ} \mathrm{C}$ for at least $1 \mathrm{~h}$.

3. Heat the surfaces of the gold bag, the titanium head, and the titanium sampling tube by exposing them to a temperature of $450{ }^{\circ} \mathrm{C}$ for 4 $\mathrm{h}$ in a muffle furnace in an air atmosphere.

NOTE: This procedure sterilizes the surfaces and results in the formation of a passivating titanium dioxide layer on all titanium surfaces. The titanium parts should have a yellow to blue color after the heat treatment.

4. Anneal the gold cell to increase the flexibility of the gold by resetting small crystallization domains by applying heat with a propane torch. Heat the gold surface all around to reduce kinks in the gold that might have formed during the last shrinking of the gold bag volume in an experiment. Make sure not to heat the gold too much in one place to avoid its melting. NOTE: A red glow of the gold surface shows sufficient heating.

5. Assemble the gold bag into the titanium collar, and the titanium sampling tubing into the titanium head using a torque of $10 \mathrm{Nm}$ for the glands.

2. Inspect the high-pressure reactor. 
1. Visually check the reactor for possible damage, corrosion, and loose parts.

NOTE: Special attention should be paid to the seal and the kerf where the sealing takes place. If a graphite gasket was previously used to seal the reactor, remains of it may still be in the kerf and should be removed with a plastic pin before the next experiment.

2. Apply copper sulfide paste to the thrust bolts in the high-pressure reactor head. Ensure the grease is distributed over the whole thread.

3. Check the screw-fitting compression seal for the length of the remaining graphite packing.

\section{Filling and assembling the gold-titanium reaction cell under anoxic conditions}

1. Load the glove box.

1. Prepare the culture medium in the serum bottles according to section 1.

2. Wrap the parts of the goldtitanium reaction cell that will later be in contact with the sample in aluminum foil to minimize any potential contamination.

3. Open and unlock the antechamber of the glove box, load all the inbound material onto the moveable tray, and close and lock the front cover.

4. Evacuate the antechamber $3 x$ and flood it with high-purity nitrogen.

5. Wear a pair of gloves and get as close as possible to the inner cover. Unlock and open the inner cover to remove the inbound material from the movable tray.

6. Close and lock the inner cover.

2. Fill the gold cell.

1. Unwrap the clean gold bag and stand it up with a glass beaker, for example. Open the serum bottle containing $100 \mathrm{~mL}$ of bacterial culture and elemental sulfur.

2. Gently shake the serum bottle and transfer the bacterial culture into the gold bag.

3. Assemble the reaction cell.

1. Insert the titanium head with the attached titanium sampling tube into the titanium collar enclosing the upper rim of the gold bag. NOTE: Make sure that the sealing surface of the conical lower part of the titanium head fits in smoothly by turning it $90^{\circ}$ back and forth

2. Slide the washer and the compression bolt ring over the titanium sampling tube onto the titanium head. NOTE: Turn the compression bolt ring in the titanium collar by $30^{\circ}$ to align the flanges of the titanium collar and the thrust bolt ring.

3. Fasten the six Allen screws to the same extent to ensure an even pressure distribution of the titanium head on the uppermost rim of the gold bag in the titanium collar (i.e., the sealing surface of the reaction cell).

NOTE: Fasten the Allen screws in the compression bolt ring until hand-tight so that the torque for the opposite screws is increased first (crisscrossing) before continuing clockwise.

4. Reinstall the sampling valve at the top of the titanium tube. Fasten the connection hand-tight and make sure to close the valve.

5. Remove all parts from the glove box.

\section{Assembling the high-pressure reactor with the reaction cell}

1. Assemble the reaction cell into the reactor head.

NOTE: The installation of the high-pressure reactor comes with a very short exposure of the open end of the sampling tube to the surrounding atmosphere, as the sampling valve must be removed to guide the tube through the screw seal in the reactor head. For the installation, the reactor head should already be placed into a bench vise. A $45^{\circ}$ angle allows for easier handling. The compression seal fitting (situated in the central position of the reactor head's gage block assembly), which holds the sampling tube in place, needs to be open.

1. Remove the titanium sampling valve, the screw, and the collar on top of the sampling tube.

2. Guide the tube with the reaction cell attached through the central hole in the reactor head until about $5 \mathrm{~cm}$ of the tube pass through Slide the large screw over the tube and fasten the small collar.

NOTE: Now the reaction cell assembly cannot slide back through the reactor head and both hands are free to reinstall the sampling valve.

3. Re-attach the titanium valve.

4. Tighten the compression seal fitting.

5. Remove the reactor head from the bench vise to install it on the reactor vessel.

2. Prepare to seal the reactor.

1. Put the graphite sealing on the kerf of the reactor vessel

2. Carefully place the reactor head with the attached reaction cell onto the reactor vessel.

NOTE: The reactor head, including the thermocouple, must be carefully placed on the reactor vessel to not damage the gold bag or the thermocouple.

3. Fill the reactor vessel with a mixture of deionized and tap water (approximately in a 1:1 ratio).

4. Seal the reactor.

1. Check the collar to ensure that the lower ends of the compression bolts are not sticking out of their threads. Otherwise, the pressure vessel will not be correctly installed.

2. Lift the collar and place it around the protruding edges of the reactor headvessel interface. Gently moving the collar on it will result in a proper fit. Close the snap locks holding the collar in place.

3. Fasten the compression bolts following a crisscross pattern and increase the torque in moderate steps until the final value recommended by the manufacturer is attained. NOTE: Different highpressure reactor systems may have different torque values. 
4. Finally, fasten the compression bolts in a clockwise manner.

5. Install the high-pressure reactor in the rocking device.

NOTE: The installation of the high-pressure reactor in the rocking device is described for a custom-made model manufactured at the Federal Institute for Geosciences and Natural Resources in Hannover, Germany. Therefore, the described installation is a general guideline for devices of comparable design.

1. Mount the reactor carefully in the rocking device.

NOTE: It is best to hold the highpressure reactor by the gage block assembly parts (e.g., manometer or sampling tube screws) while lowering it into the rocking device.

2. Fixate the reactor with two clamps over a pair of long screws.

3. Place washers on each screw and tighten the clamps with screw nuts.

4. Connect the control units for the thermocouple, the pressure transducer, and the heating element. NOTE: It is important to ensure that all the wires are of sufficient length for the rocking motion and prevent contact to the heated surfaces.

5. Slide the heating element over the reactor vessel and tighten its screw lock.

NOTE: The water to pressurize the system is taken from a reservoir with a high-pressure pump. It is transferred through stainless steel capillaries into the high-pressure reactor.

NOTE: Rocking of the high-pressure reactor guarantees a thorough mixing of the reaction cell contents (i.e., the gas, fluid, and all solid phases in it). A slow rocking speed is important to prevent damage to the gold bag by fast moving solids or by deformation due to gravity effects on the flexible gold at elevated temperatures. The rocking system can rotate by close to $180^{\circ}$.

\section{Starting the experiment}

1. Check if the temperature and pressure limits in the monitoring software are set to the desired values. NOTE: In this experiment they were set to $70^{\circ} \mathrm{C}$ and $25 \mathrm{MPa}$.

2. Perform a leak check.

1. Connect the pressure pipe, a stainless-steel capillary, to the reactor head.

2. Raise the pressure to the target pressure at distinct intervals while continuously checking for leakage.

3. Hold the pressure constant until the flow rate of the pump is nearly zero.

NOTE: Beware that compressible, dissolved air in water is visible for a long time in subtle flow readings.

3. Start the heating after a successful leak check.

1. Start the logging of the pressurization pumps.

2. Adjust the set point for the heating to the desired value and start the heating with the software.

3. Regularly check all parameters and the system status.

4. Untighten the pressure pipe after reaching the target temperature.

5. Start the rocking device.

\section{Sampling the high-pressure reactor in operational mode}

1. To take a sample, attach a $5 \mathrm{~mL}$ syringe to the Luer Lock connector of the sampling valve at the top of the highpressure reactor.

2. Carefully open the valve and let the fluid sample push into the syringe by the pressure inside the highpressure reactor. Close the valve after the sampled volume reaches $1 \mathrm{~mL}$. Detach the syringe.

3. Transfer the samples in the syringe immediately into a $2 \mathrm{~mL}$ tube in a fume hood for processing.

\section{7 . Analysis of fluid sample}

NOTE: Only the steps for the less common photometric ferrozine assay (i.e., section 7.1) are described here in detail and are mentioned in the video, because the other steps are standard operation procedures in microbiology.

1. Use a ferrozine assay to photometrically determine the concentration of dissolved ferrous iron $\left(\mathrm{Fe}^{2+}{ }_{(\mathrm{aq})}\right)$ and total iron $\left(\mathrm{Fe}_{\mathrm{tot}}\right)^{15}$.

1. Prepare a series of ferrous iron standard solutions by dissolving known amounts of $\mathrm{FeSO}_{4} \cdot 7 \mathrm{H}_{2} \mathrm{O}$ in water.

2. Mix $50 \mu \mathrm{L}$ of these standard levels with $1 \mathrm{~mL}$ of a $1 \mathrm{M}$ ferrozine solution. NOTE: The reaction of ferrozine with the dissolved ferrous iron forms a purple complex. The intensity of the color correlates to the ferrous iron concentration.

3. Establish a calibration curve between the ferrous iron concentration and absorbance of the iron-ferrozine complex.

4. Calculate the concentration of ferrous iron of a sample from two parallel measurements according to the established standard curve.

2. Analyze the $\mathrm{pH}$ value and the oxidation/reduction potential (ORP) with digital $\mathrm{pH} /$ redox meters with semimicro $\mathrm{pH}$ electrodes, and a silver chloride electrode, respectively.

3. Count planktonic cells directly by using a light microscope with a Thoma chamber.

4. Investigate cell morphology by scanning electron microscopy (SEM).

1. Filter planktonic cells grown under different conditions through a $0.1-0.2 \mu \mathrm{m}$ pore size filter.

2. Dehydrate samples with acetone and store them overnight at $4{ }^{\circ} \mathrm{C}$ in $90 \%$ acetone.

3. Dry the samples by critical point drying and coat them with graphite or gold. 
4. Examine specimens with a field emission scanning electron microscope (FE-SEM) at $10 \mathrm{kV}$.

\section{Representative Results}

Results of the high-pressure reactor experiment with the special gold-titanium reaction cell show that the microbial mixed culture of acidophiles oxidized sulfur and reduced ferric iron to ferrous iron (Figure 3).

At both 1 bar or 100 bar pressure conditions, the cultures had a lag phase when grown in the gold-titanium reaction cell. After that period, a rapid increase in the ferrous iron concentration from approximately $9 \mathrm{mM}$ to $31 \mathrm{mM}$ occurred in the culture grown at 1 bar. Over the incubation time of 22 days, $\sim 31 \mathrm{mM}$ and $13 \mathrm{mM}$ of ferrous iron were detected in the assays at 1 bar and 100 bar, respectively. This clearly demonstrates that the microbial cells were active at 100 bar, but their ferric iron-reducing activity was significantly lower at elevated pressure. Abiotic control experiments conducted in Hungate tubes and serum bottles did not show ferric iron reduction at 1 bar and 100 bar.

The scanning electron microscopy images (Figure 4) show rod-shaped cells grown in experiments at low and high pressure. No significant change in the cell morphology was observed at 1 bar versus 100 bar. However, cell growth was obviously inhibited by the elevated pressure, as the cell number was $1.3 \times 10^{8} \mathrm{cells} / \mathrm{mL}$ at $1 \mathrm{bar}$ in comparison to $4.5 \times 10^{7}$ cells $/ \mathrm{mL}$ at $100 \mathrm{bar}^{7}$. These data are comparable with the tests done in Hungate tubes ${ }^{7}$. Thus, the flexible gold-titanium reaction cell itself had no effect on cell growth and was suitable for microbial growth tests.

The results show that bioleaching microorganisms are active even at a high pressure of 100 bar, which is highly relevant for in situ biomining because such conditions occur in deep ore deposits at a depth below $1,000 \mathrm{~m}^{7}$.

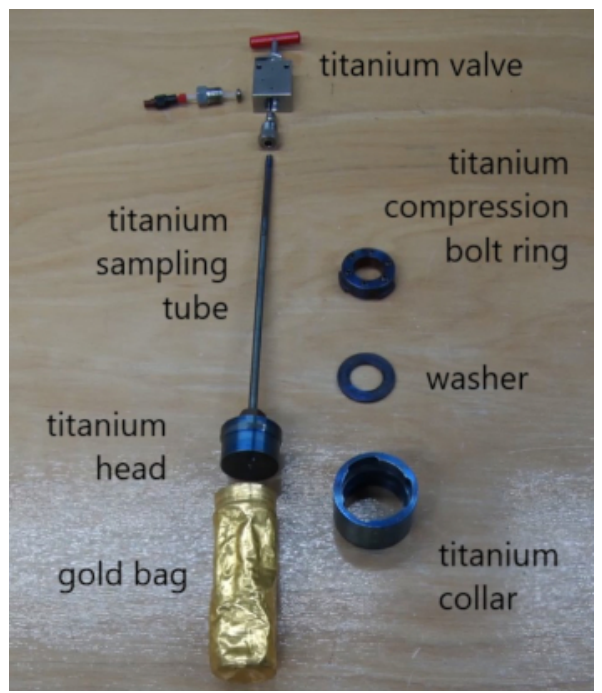

Figure 1: Overview of the reaction cell parts. From bottom to top: the gold bag, titanium collar, titanium head, washer, titanium compression bolt ring, titanium sampling tube with stainless glands and collars for the high-pressure coned and threaded connections on both sides, and the titanium valve with an adapter for connecting a Luer Lock syringe. Please click here to view a larger version of this figure.
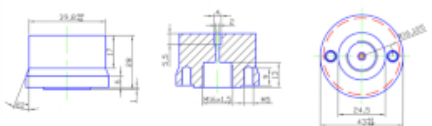

titanium collar
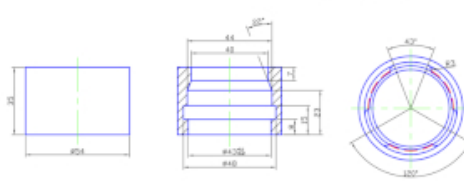

titanium

compression
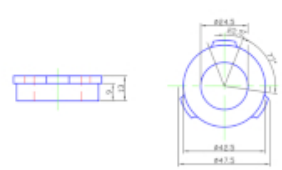

titanium washer

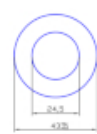

Figure 2: Dimensional drawings of the titanium parts machined from rods of titanium grade 2. Please click here to view a larger version of this figure. 


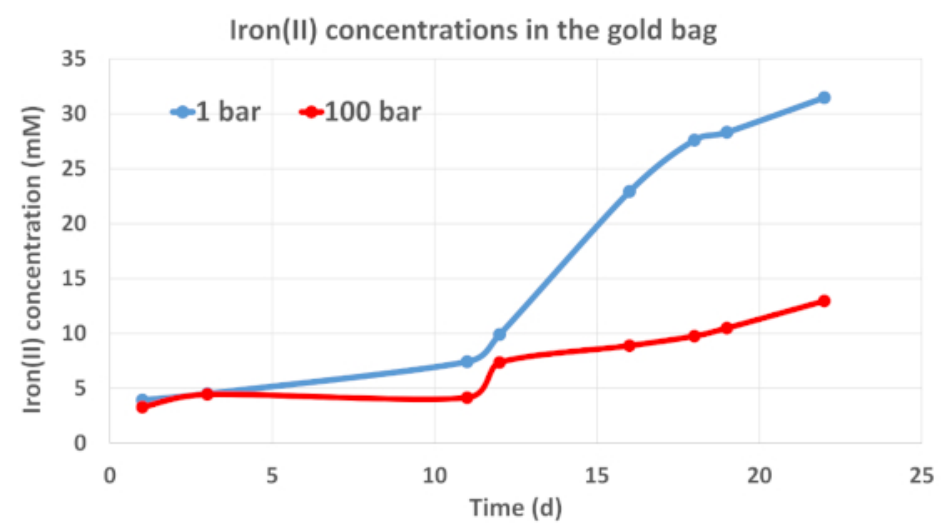

Figure 3: Changes of the ferrous iron concentrations in the gold-titanium reaction cell with the ferrous iron-oxidizing culture. Cells were cultivated anaerobically at $30^{\circ} \mathrm{C}$. Please click here to view a larger version of this figure.

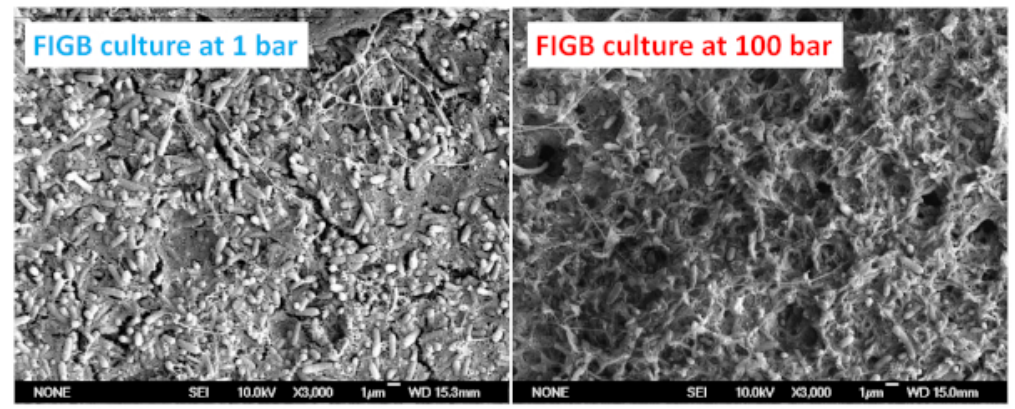

Figure 4: Morphology of the ferrous iron-oxidizing culture grown at 1 bar and 100 bar. Cells were cultivated anaerobically at $30{ }^{\circ} \mathrm{C}$. Please click here to view a larger version of this figure.

\section{Discussion}

The presented method for high-pressure experiments of microbial reactions within acidic solutions was a powerful tool to simulate deep subsurface geomicrobiological processes in a laboratory environment.

There are numerous manual work steps involved, some of which require special attention. As a general note, no excessive force must be used when assembling the individual parts of the flexible gold-titanium cell and the reactor head (sections 3 and 4 ). If the manufacturer's specifications (e.g., for maximum pressure, temperature, torque) are ignored, leakage and/or material failure may result.

Cleaning of the gold and titanium parts (section 2.2) is an indispensable work step, not only for this experiment, but especially for experiments involving (in-)organic reactions. Remnants from previous experiments in the gold cell may cause unwanted reactions and therefore biasing of results. When the assembled gold-titanium cell is installed in the reactor head, it is best to work quickly and precisely, because at this time small amounts of oxygen could enter the gold cell. Closing the sampling valve before leaving the glovebox is a good first measure to minimize the exchange between the ambient atmosphere with the interior of the gold cell.

Once the reactor is placed in the rocking device, it is important to set the rocking motion speed to $\sim 170 \%$ min. If the high-pressure reactor moves too fast, rupture of the gold cell may happen due to gravitational effects or the sharp edges of sediment or rock samples when used.

This method can be used in additional research fields. The flexible gold-titanium reaction cell has the potential to be used for a diverse set of scientific investigations ${ }^{9}$ studying reactions at elevated pressure and temperature and in highly corrosive fluids or gases.

Microorganisms in the deep subsurface at temperatures above $70^{\circ} \mathrm{C}$ in the presence of mineral surfaces may stimulate the production of molecular hydrogen or organic acids like acetate even under elevated pressure ${ }^{16}$. These products, and other compounds, might induce elevated microbial activity during in situ bioleaching processes, in addition to the sulfur compounds investigated in this study.

Applications include the determination of solubility of gases and ions in aqueous fluids, geochemical reactions at conditions of hydrothermal vent systems ${ }^{17}$, the quantification of isotope fractionation ${ }^{18}$, geochemical reactions during $\mathrm{CO}_{2}$ sequestration ${ }^{19}$, abiotic processes during the formation of oil and gas in source rocks ${ }^{20}$, and microbial reactions at elevated pressures in the subsurface ${ }^{21}$ as in the present study.

\section{Disclosures}

The authors have nothing to disclose. 


\section{Acknowledgments}

We thank Robert Rosenbauer (USGS, Menlo Park) in sharing his expertise on the flexible gold-titanium reaction cells, and Georg Scheeder (BGR) for his input during the initial phase of setting up the modified system in Hannover. We would like to thank many scientists (including Katja Heeschen, Andreas Risse, Jens Gröger-Trampe, Theodor Alpermann) using the setup in Hannover in numerous projects that contributed in little improvements along the way and Christian Seeger for developing the rocking device for the high-pressure reactors. We thank Laura Castro (Complutense University of Madrid) for SEM observations. And finally, we would like to express our gratitude to Nils Wölki for producing this highquality video for the article. This work was supported by the European Union Horizon 2020 project BIOMOre (Grant agreement \# 642456).

\section{References}

1. Johnson, D. B. Biomining goes underground. Nature Geoscience. 8 (3), 165-166 (2015).

2. Bellenberg, S. et al. Manipulation of pyrite colonization and leaching by iron-oxidizing Acidithiobacillus species. Applied Microbiology and Biotechnology. 99 (3), 1435-1449 (2014).

3. Christel, S., Fridlund, J., Watkin, E. L., Dopson, M. Acidithiobacillus ferrivorans SS3 presents little RNA transcript response related to cold stress during growth at $8^{\circ} \mathrm{C}$ suggesting it is a eurypsychrophile. Extremophiles. 20 (6), 903-913 (2016).

4. Dopson, M., Ossandon, F. J., Lovgren, L., Holmes, D. S. Metal resistance or tolerance? Acidophiles confront high metal loads via both abiotic and biotic mechanisms. Frontiers in Microbiology. 5, 157 (2014).

5. Schippers, A. et al. Biomining: metal recovery from ores with microorganisms. Advances in Biochemical Engineering/Biotechnology. 141, $1-47$ (2014).

6. Shiers, D., Ralph, D., Bryan, C., Watling, H. Substrate utilisation by Acidianus brierleyi, Metallosphaera hakonensis and Sulfolobus metallicus in mixed ferrous ion and tetrathionate growth media. Minerals Engineering. 48, 86-93 (2013).

7. Zhang, R., Hedrich, S., Ostertag-Henning, C., Schippers, A. Effect of elevated pressure on ferric iron reduction coupled to sulfur oxidation by biomining microorganisms. Hydrometallurgy. 178, 215-223 (2018).

8. Dickson, F., Blount, C. W., Tunell, G. Use of hydrothermal solution equipment to determine the solubility of anhydrite in water from 100 degrees $C$ to 275 degrees $C$ and from 1 bar to 1000 bars pressure. American Journal of Science. 261 (1), 61-78 (1963).

9. Seyfried, W., Gordon, P., Dickson, F. A new reaction cell for hydrothermal solution equipment. American Mineralogist. 64 (5-6), 646-649 (1979).

10. Cross, M. M., Manning, D. A., Bottrell, S. H., Worden, R. H. Thermochemical sulphate reduction (TSR): experimental determination of reaction kinetics and implications of the observed reaction rates for petroleum reservoirs. Organic Geochemistry. 35 (4), $393-404$ (2004).

11. Frerichs, J., Rakoczy, J., Ostertag-Henning, C., Krüger, M. Viability and adaptation potential of indigenous microorganisms from natural gas field fluids in high pressure incubations with supercritical $\mathrm{CO}_{2}$. Environmental Science \& Technology. 48 (2), 1306-1314 (2014).

12. Heeschen, K., Risse, A., Ostertag-Henning, C., Stadler, S. Importance of co-captured gases in the underground storage of $\mathrm{CO}_{2}$ : Quantification of mineral alterations in chemical experiments. Energy Procedia. 4, 4480-4486 (2011).

13. Wakeman, K., Auvinen, H., Johnson, D. B. Microbiological and geochemical dynamics in simulated-heap leaching of a polymetallic sulfide ore. Biotechnology and Bioengineering. 101 (4), 739-750 (2008).

14. Pakostova, E., Grail, B. M., Johnson, D. B. Indirect oxidative bioleaching of a polymetallic black schist sulfide ore. Minerals Engineering. 106, 102-107 (2017).

15. Lovley, D. R., Phillips, E. J. Rapid assay for microbially reducible ferric iron in aquatic sediments. Applied and Environmental Microbiology. $\mathbf{5 3}$ (7), 1536-1540 (1987).

16. Parkes, R. J. et al. Prokaryotes stimulate mineral $\mathrm{H}_{2}$ formation for the deep biosphere and subsequent thermogenic activity. Geology. 39 (3), 219-222 (2011).

17. McCollom, T. M. Abiotic methane formation during experimental serpentinization of olivine. Proceedings of the National Academy of Science of the United States of America. 113 (49), 13965-13970 (2016).

18. Pester, N. J., Conrad, M. E., Knauss, K. G., DePaolo, D. J. Kinetics of D/H isotope fractionation between molecular hydrogen and water. Geochimica et Cosmochimica Acta. 242, 191-212 (2018).

19. Rosenbauer, R. J., Thomas, B., Bischoff, J. L., Palandri, J. Carbon sequestration via reaction with basaltic rocks: Geochemical modeling and experimental results. Geochimica et Cosmochimica Acta. 89, 116-133 (2012).

20. Knauss, K. G., Copenhaver, S. A., Braun, R. L., Burnham, A. K. Hydrous pyrolysis of New Albany and Phosphoria Shales: production kinetics of carboxylic acids and light hydrocarbons and interactions between the inorganic and organic chemical systems. Organic Geochemistry. 27 (7-8), 477-496 (1997).

21. Parkes, R. J. et al. Culturable prokaryotic diversity of deep, gas hydrate sediments: first use of a continuous high-pressure, anaerobic, enrichment and isolation system for subseafloor sediments (DeeplsoBUG). Environmental Microbiology. 11 (12), $3140-3153$ (2009). 